\title{
A low resting heart rate at diagnosis predicts favourable long-term outcome in pulmonary arterial and chronic thromboembolic pulmonary hypertension. A prospective observational study
}

\author{
Florian F Hildenbrand ${ }^{1}$, Ivan Fauchère ${ }^{2}$, Lars C Huber ${ }^{1}$, Stephan Keusch ${ }^{1}$, Rudolf Speich ${ }^{2}$ and Silvia Ulrich ${ }^{1,3^{*}}$
}

\begin{abstract}
Background: A low resting heart rate (HR) is prognostically favourable in healthy individuals and in patients with left heart disease. In this study we investigated the impact of HR at diagnosis on long-term outcome in patients with differently classified precapillary pulmonary hypertension (pPH).

Methods: pPH patients diagnosed as pulmonary arterial (PAH) or inoperable chronic thromboembolic pulmonary hypertension (CTEPH) were registered and regularly followed at our centre Baseline characteristics and events defined as either death or lung transplantation were noted. The prognostic value of HR was analysed using Kaplan Meier estimates, live tables and Cox regression.

Results: 206 patients with PAH (148) and inoperable CTEPH (58) were included. The median HR was 82 bpm. pPH with a HR below 82 bpm had a significantly longer overall event-free survival (2409 vs.1332 days, $p=.000$ ). This advantage was similarly found if PAH and CTEPH were analysed separately. Although a lower HR was associated with a better hemodynamic and functional class, HR was a strong and independent prognostic marker for transplant free survival even if corrected for age, sex, hemodynamics and functional status.

Conclusion: We show that resting HR at diagnosis is a strong and independent long-term prognostic marker in PAH and CTEPH. Whether reducing HR by pharmacological agents would improve outcome in PPH has to be assessed by future trials with high attention to safety.
\end{abstract}

Keywords: Chronic thromboembolic pulmonary hypertension, Heart rate, Prognosis, Pulmonary hypertension, Pulmonary arterial hypertension

\section{Background}

A lower resting heart rate $(\mathrm{HR})$ is prognostically favourable in healthy individuals or in patients with cardiovascular disease [1-3]. An increased HR is an independent risk factor for cardiovascular and all-cause mortality in cardiovascular disease and left heart failure (LHF) $[2,4]$. In patients with systolic heart failure, the resting HR-threshold over which an increased mortality was found, was as low as $70 \mathrm{bpm}[1]$.

\footnotetext{
*Correspondence: silvia.ulrich@usz.ch

'Department of Heart, Vessel, Thorax, University Hospital of Zurich, Zurich 8091, Switzerland

${ }^{3}$ Center for Integrative Human Physiology, University of Zurich, Zurich, Switzerland

Full list of author information is available at the end of the article
}

The prognostic role of the HR in right sided heart failure due to precapillary pulmonary hypertension ( $\mathrm{pPH}$ ) is less clear. Studies have shown that an increased resting HR was a marker for disease burden and herewith associated with an unfavourable prognosis in patients with pulmonary arterial hypertension (PAH) [5,6]. Compared to healthy and to patients with left heart disease the cut off value for an adverse prognosis was higher in PAH (HR $82 \mathrm{bpm}$ or $87 \mathrm{bpm}$ in untreated and $92 \mathrm{bpm}$ in specifically treated patients) $[5,6]$. The pathogenesis underlying a relatively increased HR in PAH is not completely understood. It is thought that the increased right ventricular afterload leads to an impaired right ventricular stroke volume. This reduced stroke volume will lead 
mainly via sympathetic activation to an increased HR, so that the cardiac output can be maintained in order to provide sufficient oxygen to the body, especially during exercise [7]. The increased HR in PAH might therefore rather be a consequence of disease burden and not an independent marker for adverse prognosis [6]. However, the increased sympathetic response along with the increased HR may unfavourably affect ventricular remodelling [5]. Until now it is not clear whether a lower $\mathrm{HR}$ is an independent prognostic factor in a broader $\mathrm{pPH}$ collective. We therefore aimed to investigate the prognostic value of the resting HR on long-term outcome in patients with differently classified $\mathrm{pPH}$ including $\mathrm{PAH}$ and inoperable chronic thromboembolic $\mathrm{PH}$ (CTEPH) $[8,9]$.

\section{Methods}

Patients who were diagnosed with $\mathrm{pPH}$ by right heart catheterisation (RHC) and classified in PAH or CTEPH by WHO [8] gave their written informed consent to have their data prospectively registered. Quality of life, NYHA/WHO functional class and 6 minute walk distance (6MWD) were assessed and registered at baseline [10]. During the diagnostic RHC, the following parameters were recorded as average of two separate measures during a stable period for at least 15 minutes recumbent rest: arterial blood pressures, resting HR, pulmonary artery pressures, right atrial pressure, pulmonary capillary occlusion pressure and cardiac output by continuous thermodilution. Mean pulmonary and systemic arterial pressures (mPAP and mAP), systemic and pulmonary vascular resistance (SVR and PVR) and cardiac index (CI) were calculated. Mixed venous and arterial blood samples were drawn for measures of oxygen saturations and partial pressures of oxygen and carbon dioxide. Patients were thereafter followed at our centre in close collaboration of specialists and general practitioners. Deaths of any cause and lung transplantation were defined as events. In June 2011 records of every single patient were reviewed for correct event recording and doublechecked with the clinical report. If there were any doubt about events the general practitioner was contacted to assure life or occurrence of events. Patients with operable CTEPH who underwent pulmonary embolectomy were excluded from the survival analysis as the indication to operate is not merely correlated to disease severity.

The study was performed according to the Declaration of Helsinki, ICH-GCP as well as all national legal and regulatory requirements. National and international guidelines did not require institutional review board approval because this study was retrieved from our prospective registry.

\section{Statistics}

All baseline data is summarized by mean \pm standard deviation (SD) or medians (quartiles). Baseline variables by groups were compared using Mann-Witney-U-Test and Fisher-Test. Differential survival was assessed by Kaplan Meyer analysis and live tables, significance was tested by log-rank test and fishers test. Cox regression analysis was used for multivariate survival analysis. A p $<0.05$ was considered significant. SPSS 19.0.0 (SPPS, Inc., Chicago Illinois) and Excel were used.

\section{Results}

\section{Patients' characteristics}

222 patients with $\mathrm{pPH}$ having had baseline evaluation with diagnostic RHC between January 1998 and June 2011 were included. 16 patients with subsequent pulmonary endarterectomy were excluded according to the protocol.

Characteristics of the remaining $206 \mathrm{pPH}$ patients (130 females, age $55 y \pm 17 y$ ) are shown in Table 1.148 had PAH (55 idiopathic, 32 collagen vascular, 61 other associated) and 58 had inoperable CTEPH. Patients were in NYHA II to IV with a markedly reduced baseline 6MWD $(386 \pm 137 \mathrm{~m})$. The mean baseline resting HR was $82 \pm 14 \mathrm{bpm}$, the mPAP was $45 \pm 18 \mathrm{mmHg}$ and PVR $775 \pm 464$ dyn*s* $\mathrm{m}^{-5}$. Conventional medical treatment at baseline consisted of diuretics and oral anticoagulation. After baseline evaluation $\mathrm{HR}$ assessment, the following treatments had been started: Endothelin-1 receptor antagonists (85), Phosphodiesterase inhibitors (34), inhaled (63) or parenteral Prostanoids (8) and calcium antagonists (37, positive responders to acute vasodilator therapy, mostly switched to other therapies during follow-up.

During the median follow-up of $37(18 ; 64)$ months, 24 patients died (18 PAH and 6 inoperable CTEPH), and 3 received lung transplantation ( $1 \mathrm{PAH}$ and $2 \mathrm{CTEPH}$ ). Median overall survival was 4.8 years.

\section{Differences between pulmonary arterial and inoperable chronic thromboembolic $\mathrm{pPH}$}

Patients with $\mathrm{PAH}$ were significant younger at baseline compared to CTEPH (51 \pm 18 vs. $61 \pm 12$ y, p = 0.008) and had a higher mixed venous oxygen saturation $\left(\mathrm{SmvO}_{2} 61 \pm 11\right.$ vs. $\left.57 \pm 10, \mathrm{p}=0.014\right)$. We found no other baseline differences and the overall event-free survival were similar in both classes (median 1776 vs. 1653 days, $\mathrm{p}=0.47)$.

\section{Baseline and outcome difference according to resting heart rate}

Patients characteristic for patients with resting HR below and above the median of $82 \mathrm{bpm}$ are shown in Table 2. Patients with higher HR had less favourable 
Table 1 Patients' baseline characteristics

\begin{tabular}{|c|c|}
\hline & Numbers (\%) Mean \pm SD \\
\hline Total number of patients & 206 \\
\hline Female/male & $130 / 76(63 / 37)$ \\
\hline Age (years) & $55 \pm 17$ \\
\hline \multicolumn{2}{|l|}{$\begin{array}{l}\text { Precapillary Pulmonary arterial } \\
\text { hypertension: }\end{array}$} \\
\hline -Idiopathic & $55(27)$ \\
\hline -Associated to collagen vascular disease & $32(16)$ \\
\hline -Other associated PAH & $61(30)$ \\
\hline $\begin{array}{l}\text {-Chronic thromboembolic PH not } \\
\text { eligible for surgery }\end{array}$ & $58(28)$ \\
\hline NYHA functional class $1 / / I / I I / / V$ & $1 / 37 / 104 / 62(1 / 18 / 51 / 30)^{*}$ \\
\hline $\mathrm{BMI}\left(\mathrm{kg} / \mathrm{m}^{2}\right)$ & $25 \pm 5$ \\
\hline Mean resting heart rate (bpm) & $82 \pm 14$ \\
\hline Mean arterial pressure $(\mathrm{mmHg})^{+}$ & $90 \pm 14$ \\
\hline $\begin{array}{l}\text { Mean pulmonary arterial } \\
\text { pressure }(\mathrm{mmHg})^{\dagger}\end{array}$ & $45 \pm 18$ \\
\hline $\begin{array}{l}\text { Pulmonary vascular resistance } \\
\left(\text { dyn }^{*} \sec ^{*} m^{-5}\right)^{\dagger}\end{array}$ & $775 \pm 464$ \\
\hline Cardiac index $\left(1 / \mathrm{min} / \mathrm{m}^{2}\right)^{+}$ & $2.4 \pm 0.8$ \\
\hline Right atrial pressure $(\mathrm{mmHg})^{+}$ & $9 \pm 6$ \\
\hline NT-pro-BNP (ng/l, < 130) & $1826 \pm 2269$ \\
\hline 6 minute walking distance $(\mathrm{m})$ & $386 \pm 137$ \\
\hline Mean follow up (months) & $45 \pm 35$ \\
\hline Percentage survivors at year $1,3,5,7,9$ & $84 / 67 / 57 / 55 / 53$ \\
\hline \multicolumn{2}{|l|}{ Medication after baseline: } \\
\hline -Calcium antagonist & $37(18)$ \\
\hline -Prostacyclin analogues (by inhalation) & $63(31)$ \\
\hline -Prostacyclin analogues (parenteral) & $8(4)$ \\
\hline -Endothelin-1 receptor antagonist & $96(47)$ \\
\hline -Phosphodiesterase inhibitor & $34(17)$ \\
\hline
\end{tabular}

* For two patients data were not registered, ${ }^{+}$measured by right heart catheter; Data is given as number (\%) or mean \pm SD. NYHA: New York Heart Association, WHO: World health organization, BMI: Body mass index, NT-pro-BNP: NT-pro brain natriuretic peptide.

hemodynamics, i.e. higher mPAP and PVR and lower SmvO2.

We found a significantly longer event-free survival for patients with a HR below $82 \mathrm{bpm}(\log$ rank $\mathrm{p}=0.006$, Figure 1). After 10 years, 61 (60\%) patients with a baseline HR below $82 \mathrm{bpm}$ were still alive compared with 48 (46\%) of patients with a HR $\geq 82 \mathrm{bpm}$. Consequently, the median transplant-free survival was significantly lower if the baseline $\mathrm{HR}$ was $\geq 82 \mathrm{bpm}$ compared to $<82$ bpm (1581 vs. 2660 days, $\mathrm{p}<0.0001)$. This significant event-free survival difference persisted even if PAH and CTEPH were analysed separately $(\mathrm{p}=0.027$ and $\mathrm{p}<0.001)$. Analysis of the idiopathic and collagen vascular disease associated $\mathrm{PAH}$ subgroups revealed that a significant survival difference was found up to 8 and 5 years, respectively, but not thereafter due to the small number of cases at risk.

If, in analogy to left heart failure studies $[1,3]$, lower cut off levels for the resting HR were taken, patients with lower resting $\mathrm{HR}$ cut offs had more favourable hemodynamics compared to patients above the cut off, Figure 2. Thus, for thresholds of 70 or $75 \mathrm{bpm}$, the mPAP measures were $40 \pm 14$ and $42 \pm 13$ compared with $49 \pm 17$ and $50 \pm 17 \mathrm{mmHg}$ ( $\mathrm{p}=0.002$ and .008 , respectively); the calculated PVR was $594 \pm 402$ and $643 \pm 407$ vs. $816 \pm 453$ and $834 \pm 459$ dyn* $\mathrm{s}^{*} \mathrm{~m}^{-5}$ ( $\mathrm{p}=0.004$ and $\left.\mathrm{p}=0.003\right)$. Median survival were 2008 and 1766 vs. 4028 and 3170 days for cut offs of 70 and $75 \mathrm{bpm}(\mathrm{p}=0.087$ and $\mathrm{p}=0.002)$, respectively. The cumulative Kaplan Meyer survival differences did not reach statistical significance for the cut off of $70 \mathrm{bpm}$ ( $\log$ rank $\mathrm{p}=0.069$ ) but highly significant for the cut off of $75 \mathrm{bpm}$. A relatively high HR cut off of $92 \mathrm{bpm}$ still revealed an advantage for patients with a HR below this value $(\mathrm{p}=0.001)$.

\section{Multivariate survival analysis}

In a multivariate Cox regression model including sex, age, PVR and HR, the resting HR was the strongest independent survival predictor $(\mathrm{p}<0.0001)$. Baseline resting $H R$ remained the strongest independent predictor of survival even when WHO functional class or the 6MWD were additionally included in the model $(\mathrm{p}<0.0001$ and $\mathrm{p}=0.002$ ). Resting HR persisted as strongest independent predictor even if the PVR was replaced by the cardiac index $(\mathrm{p}<0.0001)$ or the right atrial pressure $(\mathrm{p}=.002)$ in the multivariate regression model.

\section{Discussion}

In this long-time follow up collective of well characterized patients with $\mathrm{PAH}$ and CTEPH we found that a low resting $\mathrm{HR}$ at diagnosis was a strong and independent predictor of a favourable long-term outcome overall and for both groups separately. pPH patients with a resting $\mathrm{HR}$ below thresholds of 75 to $82 \mathrm{bpm}$ had a markedly and significantly prolonged median survival compared to patients with higher resting HR. A lower resting HR remained an independent predictor of favourable outcome even if corrected for demographics, pulmonary hemodynamic, exercise capacity and functional class.

Many epidemiological studies in left heart failure have shown that a reduction of the HR improves cardiovascular outcome [1,3], implicating that an increased $\mathrm{HR}$ might not only be a mere compensatory mechanism, but, rather more, might represent an adverse factor on cardiac hemodynamics itself. The underlying mechanisms are not fully elucidated.

One explanation might be that the decreased diastolic filling time due to a shortened heart cycle does not allow 
Table 2 Difference in baseline characteristics by median resting heart rate

\begin{tabular}{|c|c|c|c|}
\hline & $<82$ bpm Numbers (\%) Mean \pm SD & $>82$ bpm Numbers (\%) Mean \pm SD & $\mathrm{p}$ \\
\hline Total number of patients & 101 & 105 & 0.780 \\
\hline Female/male & $60 / 41(59 / 41)$ & $70 / 35(67 / 33)$ & $0.64 / 0.5$ \\
\hline Age (years) & $57 \pm 17$ & $54 \pm 16$ & 0.158 \\
\hline Idiopathic & $24(24)$ & $31(30)$ & 0.345 \\
\hline Connective tissue disease & $15(15)$ & $17(16)$ & 0.724 \\
\hline Other PAH & $29(29)$ & $32(31)$ & 0.701 \\
\hline $\begin{array}{l}\text { Chronic thromboembolic PH not } \\
\text { eligible for surgery }\end{array}$ & $33(33)$ & $25(24)$ & 0.294 \\
\hline WHO functional class I/II/III/IV & 0/20/54/25 (20/54/25) & $1 / 17 / 50 / 37(16 / 48 / 35)$ & $0.59 / 0.71 / 0.30$ \\
\hline $\mathrm{BMI}(\mathrm{kg} / \mathrm{m} 2)$ & $25 \pm 5$ & $25 \pm 6$ & 0.545 \\
\hline Resting Heart Rate (bpm) & $71 \pm 7$ & $93 \pm 9$ & $<0.001^{* *}$ \\
\hline Mean arterial pressure $(\mathrm{mmHg})^{\dagger}$ & $88 \pm 14$ & $91 \pm 14$ & 0.116 \\
\hline $\begin{array}{l}\text { Mean pulmonary arterial } \\
\text { pressure }(\mathrm{mmHg})^{+}\end{array}$ & $42 \pm 16$ & $48 \pm 19$ & $0.04^{*}$ \\
\hline $\begin{array}{l}\text { Pulmonary vascular } \\
\text { resistance }\left(\text { dyn* } \sec ^{*} m-5\right)^{\dagger}\end{array}$ & $661 \pm 396$ & $884 \pm 499$ & $0.01^{*}$ \\
\hline Cardiac index $(1 / \mathrm{min} / \mathrm{m} 2)^{+}$ & $2.5 \pm 0.8$ & $2.2 \pm 0.8$ & 0.18 \\
\hline Right atrial pressure $(\mathrm{mmHg})^{+}$ & $7 \pm 5$ & $11 \pm 7$ & $<0.001^{* *}$ \\
\hline NT-pro-BNP (ng/l, < 130) & $1593 \pm 2079$ & $2043 \pm 2429$ & 0.283 \\
\hline 6 minute walking distance $(\mathrm{m})$ & $409 \pm 141$ & $366 \pm 131$ & 0.11 \\
\hline Mean follow up (days) & 1530 & 1179 & 0.15 \\
\hline Percentage survivors at year $1,3,5,7,9$ & $93 / 78 / 68 / 64 / 62$ & $77 / 57 / 49 / 48 / 47$ & 0.40/0.18/0.19/0.23/0.28 \\
\hline Median survival (years) & 6.6 & 3.7 & $<0.001^{* *}$ \\
\hline
\end{tabular}

* Significant, ${ }^{* *}$ highly significant ${ }^{+}$measured by right heart catheter;

Data is given as number (\%) or mean \pm SD. NYHA: New York Heart Association, WHO: World health organization, BMI: Body mass index, NT-pro-BNP: NT-pro brain natriuretic peptide.
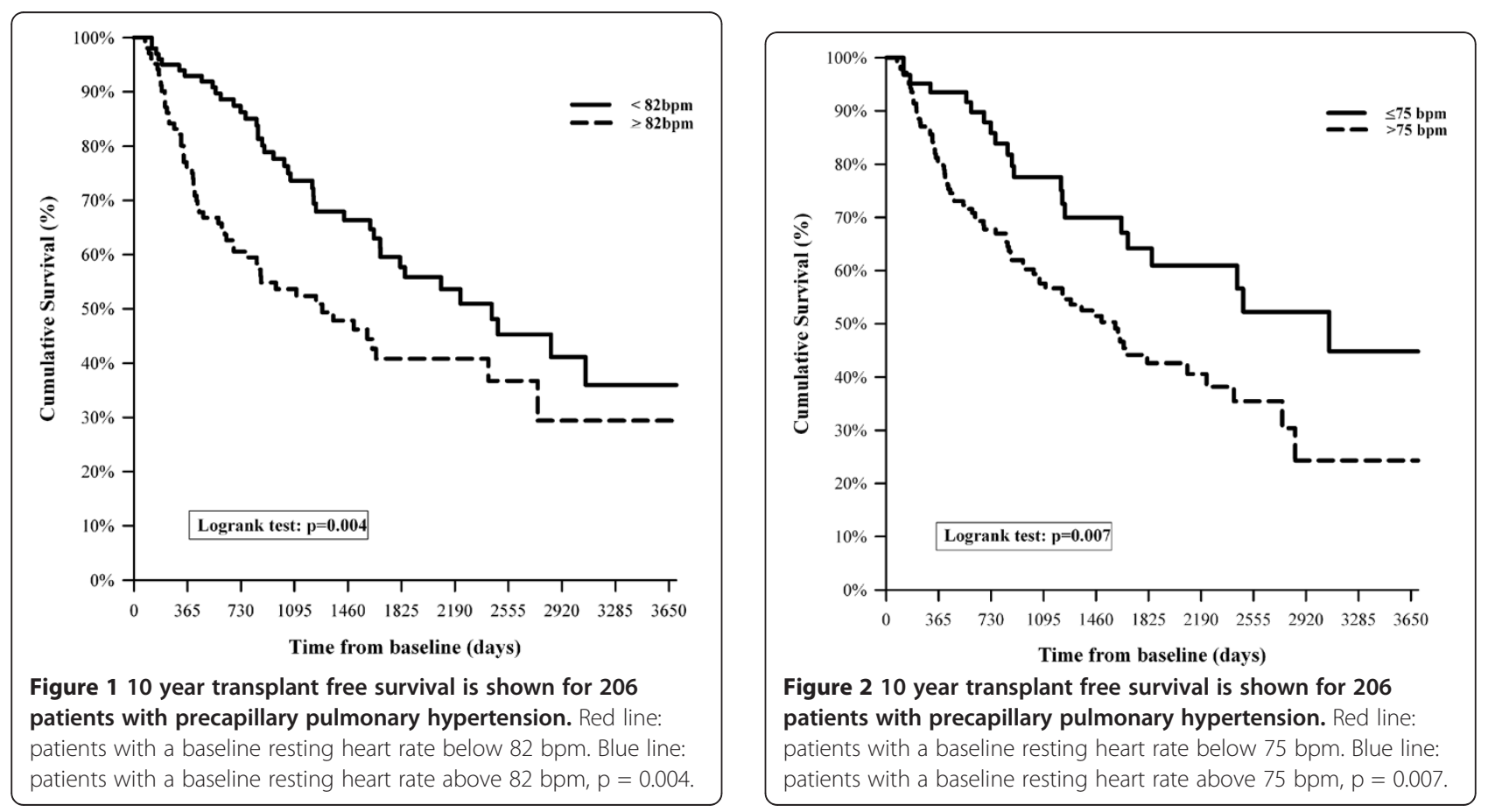
sufficient myocardial perfusion to supply adequate oxygen to the diseased heart. Another reason might be that the augmented sympathetic activity leading to an increased HR is overshooting and, in turn, has adverse effects itself. The fact that not only sympathetic blockade by beta receptor blockers, but also mere HR reduction by Ion channel modification, result in a better outcome in patients with left heart failure points against the hypothesis of a single sympathetic adverse effect responsible for higher HR along with unfavourable outcomes $[11,12]$.

In this study we could demonstrate that a lower resting HR is not only a favourable prognostic factor in patients with left heart failure, but also in patients with right heart failure due to differently classified pPH. Although patients with a lower resting HR had a better hemodynamic profile, functional class and relatively preserved exercise capacity, the fact that the resting HR remained an independent prognostic factor even if corrected for age, sex, pulmonary vascular resistance, exercise and functional capacities underscores that resting HR not only reflects the degree of disease burden but represents an independent predictor by itself in patients with $\mathrm{pPH}$.

Although several studies linked a lower resting HR to longevity in healthy individuals and especially in patients with left heart disease $[1,2,13,14]$, the assessment of HR thresholds, at which risk may increase, has not been the focus of studies until recent publications $[1,15]$. Moreover, the prognostic value of $\mathrm{HR}$ in major groups such as heart failure with preserved ejection fraction was only recently addressed [15]. These studies in LHF showed that a resting HR threshold as low as $70 \mathrm{bpm}$ was prognostically discriminative. In the present study including patients with $\mathrm{pPH}$, we tested several resting HR cut off points based on the median HR and in comparison with previously published cohorts of patients with left heart failure, where a cut off of $70 \mathrm{bpm}$ was found [1], and a published cohort of idiopathic PAH, were a HR thresholds of $80 \mathrm{bpm}$ was assessed [6]. In analogy to the later cohort, we found that a baseline resting HR above $82 \mathrm{bpm}$, the median in our cohort, was independently associated with increased mortality. We can therefore extend these published results to a broader and clinical relevant and realistic pPH population including associated PAH and CTEPH. Reducing the HR threshold to $75 \mathrm{bpm}$ even better identified patients with a more favourable prognosis. A further threshold decrease to $70 \mathrm{bpm}$ in analogy to published data in left heart disease, did not significantly differentiate the prognosis, most probably due to the small sample size, since only few patients in our cohort had resting HR below $70 \mathrm{bpm}$.

Recent guidelines do not include HR as prognostic marker, as the prognostic significance of $H R$ in right heart failure due to pulmonary vascular disease had not been sufficiently studied $[9,16]$. Our data can fill this cap by showing that resting HR is an independent prognostic marker irrespective of demographics, hemodynamics and functional class. We herewith advocate that HR should be integrated in the clinical management, guidelines and trials including $\mathrm{pPH}$ patients.

At physiological pressures, the thin-walled, highly compliant RV can accommodate with high volumes (preload-dependency) [17]. However, in pPH the markedly increased RV afterload stresses the RV and results in inefficient work, especially during exercise. The capability to increase HR during exercise is therefore thought to be a key factor to maintain cardiac output. Therefore, most experts agreed for decades that agents which reduce HR and remove the body's possibility to react with a chronotropic response towards the increased RV afterload are contraindicated in $\mathrm{pPH}[18,19]$. In addition, the most frequently used agents to control HR, the beta adrenergic receptor blocker, could induce pulmonary vasoconstriction. However, several recent studies indicate that the beta-adrenergic system is over stimulated in $\mathrm{pPH}$ and this overstimulation may lead to a maladaptive RV remodelling as found in $\mathrm{pPH}[18,19]$. Furthermore, supraventricular tachyarrhythmias are frequently found in $\mathrm{pPH}$ and associated with increased morbidity [20]. Beta adrenergic receptor blocker therapy have been shown to reduce mortality by about a third in left heart disease regardless of disease severity $[21,22]$. Reducing HR in left heart disease by this therapy reverses the maladaptive cardiac remodelling (at least partially), improves cardiac function and prevents arrhythmias [23]. However, these agents are either not mentioned in $\mathrm{pPH}$ guidelines or their use discouraged for fear of detrimental effects on hemodynamics due to the reduced chronotropic response, especially during exercise $[16,24,25]$. It may well be that these negative short-term effects of beta adrenergic blockage could be overcome by a reversal of the maladaptive cardiac remodelling, as suggested by data from a pPH animal model [19]. Theoretically, a HR decrease could also improve RV function by prolonging the relative duration of diastolic filling. This would allow a better coronary perfusion and oxygen delivery to the hypertrophied and often hypoperfused myocardium and may lead to an improved RV systolic function. Whether a treatment strategy aimed at slowing resting HR and reducing the increased betaadrenergic response in pPH would be beneficial in $\mathrm{pPH}$ is still unclear. The results of our long-term study in $\mathrm{pPH}$ and other studies in idiopathic PAH showed that a reduced HR is prognostically important. Whether the medicamentous reduction of HR in pPH would be beneficial in $\mathrm{pPH}$ remains to be elucidated by future, well designed trial with special attention to the safety of such agents.

Our study is relatively small, however, $\mathrm{pPH}$ is a rare disease and we can provide robust long-term flow-up 
data in a thoroughly investigated and well followed pPH collective. Resting HR was carefully obtain after at least 10 minutes of rest with stable continuous hemodynamic curves on the monitor over at least 10 minutes.

\section{Conclusions}

In summary, our data show for the first time that baseline resting heart rate is a strong and independent longterm prognostic factor in a broad pPH collective including $\mathrm{PAH}$ and CTEPH. Whether reducing $\mathrm{HR}$ by pharmacological agents would improve outcome in $\mathrm{pPH}$ has to be assessed by future designed trials with high attention to safety.

\begin{abstract}
Abbreviations
6MWD: 6 minute walk distance; Cl: Cardiac Index; CTEPH: Chronic Thromboembolic Pulmonary Hypertension; HR: Heart Rate; LHF: Left Heart Failure; mAP: Mean Arterial Pressure; mPAP: Mean Pulmonary Arterial Pressure; NYHA: New York Heart Association; PAH: Pulmonary Arterial Hypertension; PPH: Precapillary Pulmonary Hypertension; PVR: Pulmonary Vascular Resistance; RHC: Right Heart Catheterisation; SVR: Systemic Vascular Resistance; WHO: World Health Organisation.
\end{abstract}

\section{Competing interests}

The authors declare that they have no competing interests.

\section{Authors' contributions}

All authors had full access to the data and read and approved the final manuscript. FFH was involved in acquisition of data, analysis and interpretation of data, drafting the manuscript and revising it critically for important intellectual content and provided final approval of the version to be published. IF was involved in the interpretation of data and critical reading and revision of the draft manuscript, and final approval of the manuscript. LCH and SK made substantial contributions to the current study and publication, participating in the study process, analysis of data, development and revisions of the manuscript and has approved the final manuscript draft. $R S$ was involved in the interpretation of data and critical reading and revision of the draft manuscript. SU developed the concept of this study, was involved in analysing the data, carried out the statistical analysis and participated in the interpretation, the critical revision of the study and final approval of the manuscript.

\section{Acknowledgements}

We thank Ulla Treder and Sara Mettler for their excellent nursing assistance.

\section{Author details}

'Department of Heart, Vessel, Thorax, University Hospital of Zurich, Zurich 8091, Switzerland. 'Department of Internal Medicine and Oncology, University Hospital of Zurich, Zurich, Switzerland. ${ }^{3}$ Center for Integrative Human Physiology, University of Zurich, Zurich, Switzerland.

Received: 1 March 2012 Accepted: 19 July 2012

Published: 3 September 2012

\section{References}

1. Bohm M, Swedberg K, Komajda M, Borer JS, Ford I, Dubost-Brama A, Lerebours $G$, Tavazzi $L$ : Heart rate as a risk factor in chronic heart failure (SHIFT): the association between heart rate and outcomes in a randomised placebo-controlled trial. Lancet 2010, 376(9744):886-894

2. Cooney MT, Vartiainen E, Laatikainen T, Juolevi A, Dudina A, Graham IM: Elevated resting heart rate is an independent risk factor for cardiovascular disease in healthy men and women. Am Heart J 2010, 159(4):612-619 e613.

3. Fox K, Ford I, Steg PG, Tendera M, Robertson M, Ferrari R: Heart rate as a prognostic risk factor in patients with coronary artery disease and leftventricular systolic dysfunction (BEAUTIFUL): a subgroup analysis of a randomised controlled trial. Lancet 2008, 372(9641):817-821.
4. Heusch G: Heart rate and heart failure. Not a simple relationship. Circ J 2011, 75(2):229-236.

5. Bossone E, Paciocco G, larussi D, Agretto A, lacono A, Gillespie BW, Rubenfire M: The prognostic role of the ECG in primary pulmonary hypertension. Chest 2002, 121(2):513-518.

6. Henkens IR, Van Wolferen SA, Gan CT, Boonstra A, Swenne CA, Twisk JW, Kamp O, van der Wall EE, Schalij MJ, Vonk-Noordegraaf A, et al: Relation of resting heart rate to prognosis in patients with idiopathic pulmonary arterial hypertension. Am J Cardiol 2009, 103(10):1451-1456.

7. Provencher S, Chemla D, Herve P, Sitbon O, Humbert M, Simonneau G: Heart rate responses during the 6-minute walk test in pulmonary arterial hypertension. Eur Respir 」 2006, 27(1):114-120.

8. Simonneau G, Galie N, Rubin L, Langleben D, Seeger W, Domenighetti G, Gibbs S, Lebrec D, Speich R, Beghetti M, et al: Clinical classification of pulmonary hypertension. J Am Coll Cardiol 2004, 43(12 Suppl S):5S-12S.

9. McLaughlin W, Archer SL, Badesch DB, Barst RJ, Farber HW, Lindner JR, Mathier MA, McGoon MD, Park MH, Rosenson RS, et al: ACCF/AHA 2009 Expert Consensus Document on Pulmonary Hypertension: A Report of the American College of Cardiology Foundation Task Force on Expert Consensus Documents and the American Heart Association Developed in Collaboration With the American College of Chest Physicians; American Thoracic Society, Inc.; and the Pulmonary Hypertension Association. J Am Coll Cardiol 2009, 53(17):1573-1619.

10. ATS statement: Guidelines for the six-minute walk test. Am J Respir Crit Care Med 2002, 166(1):111-117.

11. Heusch G: A BEAUTIFUL lesson-ivabradine protects from ischaemia, but not from heart failure: through heart rate reduction or more? Eur Heart J 2009, 30(19):2300-2301.

12. Borer JS, Le Heuzey JY: Characterization of the heart rate-lowering action of ivabradine, a selective I(f) current inhibitor. Am J Ther 2008, 15(5): 461-473.

13. Lanza GA, Fox K, Crea F: Heart rate: a risk factor for cardiac diseases and outcomes? Pathophysiology of cardiac diseases and the potential role of heart rate slowing. Adv Cardiol 2006, 43:1-16.

14. Beddhu S, Nigwekar SU, Ma X, Greene T: Associations of resting heart rate with insulin resistance, cardiovascular events and mortality in chronic kidney disease. Nephrol Dial Transplant 2009, 24(8):2482-2488.

15. Kapoor JR, Heidenreich PA: Heart rate predicts mortality in patients with heart failure and preserved systolic function. J Card Fail 2010, 16(10): 806-811.

16. Galie N, Hoeper MM, Humbert M, Torbicki A, Vachiery JL, Barbera JA, Beghetti M, Corris P, Gaine S, Gibbs JS, et al: Guidelines for the diagnosis and treatment of pulmonary hypertension: The Task Force for the Diagnosis and Treatment of Pulmonary Hypertension of the European Society of Cardiology (ESC) and the European Respiratory Society (ERS), endorsed by the International Society of Heart and Lung Transplantation (ISHLT). Eur Heart J 2009, 30(20):2493-2537.

17. Horan LG, Flowers NC, Havelda CJ: Relation between right ventricular mass and cavity size: an analysis of 1500 human hearts. Circulation 1981, 64(1):135-138

18. Bogaard HJ, Abe K, Vonk Noordegraaf A, Voelkel NF: The right ventricle under pressure: cellular and molecular mechanisms of right-heart failure in pulmonary hypertension. Chest 2009, 135(3):794-804.

19. Bogaard HJ, Natarajan R, Mizuno S, Abbate A, Chang PJ, Chau VQ, Hoke NN, Kraskauskas D, Kasper M, Salloum FN, et al: Adrenergic receptor blockade reverses right heart remodeling and dysfunction in pulmonary hypertensive rats. Am J Respir Crit Care Med 2010, 182(5):652-660.

20. Tongers J, Schwerdtfeger B, Klein G, Kempf T, Schaefer A, Knapp JM, Niehaus M, Korte T, Hoeper MM: Incidence and clinical relevance of supraventricular tachyarrhythmias in pulmonary hypertension. Am Heart J 2007, 153(1):127-132.

21. Packer M, Coats AJ, Fowler MB, Katus HA, Krum H, Mohacsi P, Rouleau JL, Tendera M, Castaigne A, Roecker EB, et al: Effect of carvedilol on survival in severe chronic heart failure. N Engl J Med 2001, 344(22):1651-1658.

22. Reiter MJ, Reiffel JA: Importance of beta blockade in the therapy of serious ventricular arrhythmias. Am J Cardiol 1998, 82(4A):91-191.

23. Hjalmarson A, Goldstein S, Fagerberg B, Wedel H, Waagstein F, Kjekshus J, Wikstrand J, El Allaf D, Vitovec J, Aldershvile J, et al: Effects of controlled-release metoprolol on total mortality, hospitalizations, and well-being in patients with heart failure: the Metoprolol CR/XL Randomized Intervention Trial in congestive 
heart failure (MERIT-HF). MERIT-HF Study Group. JAMA 2000, 283(10):1295-1302.

24. Nakamura K, Fujio H: Are adrenergic receptor blockers effective or contraindicated in pulmonary arterial hypertension? Circ J 2009, 73(12):2212-2213.

25. Peacock A, Ross K: Pulmonary hypertension: a contraindication to the use of $\beta$-adrenoceptor blocking agents. Thorax 2010, 65(5):454-455.

doi:10.1186/1465-9921-13-76

Cite this article as: Hildenbrand et al: A low resting heart rate at

diagnosis predicts favourable long-term outcome in pulmonary arterial and chronic thromboembolic pulmonary hypertension. A prospective

observational study. Respiratory Research 2012 13:76.

\section{Submit your next manuscript to BioMed Central and take full advantage of:}

- Convenient online submission

- Thorough peer review

- No space constraints or color figure charges

- Immediate publication on acceptance

- Inclusion in PubMed, CAS, Scopus and Google Scholar

- Research which is freely available for redistribution 